\title{
DE NUEVO EN TORNO A LOS PRIMEROS SIGLOS DEL OBISPADO DE PAMPLONA
}

\author{
POR \\ JUAN JOSÉ LARREA \\ Universidad del Pais Vasco
}

Me brinda la redacción de Hispania Sacra la posibilidad de añadir una páginas de réplica en el mismo número en que el profesor $\mathbf{K}$. Larrañaga publica su respuesta a mi trabajo sobre el obispado de Pamplona. Se lo agradezco doblemente. Primero por lo que tiene de cortés, y en este sentido extiendo mi agradecimiento al profesor Larrañaga que ha permitido que yo examine su texto aún inédito. Y segundo porque, a pesar de que la revistas especializadas son su escenario natural, no es corriente hoy por hoy este tipo de debates, siendo así que pueden contribuir a menudo a que las distintas posturas se afinen. Creo que éste es el caso. Con erudición, el profesor Larrañaga lleva la hipótesis que pone en relación las asistencias conciliares del obispado de Pamplona con las intervenciones armadas del ejército visigodo hasta sus últimas consecuencias, lo que permite valorarla ahora con mucha mayor precisión. Puede pues el lector interesado congratularse. Las páginas que siguen exponen mis puntos de viš sobre las cuestiones que nos separan y sobre la hipótesis mencionada. Naturalmente, en el tono escueto a que me obliga el hecho de tratarse de una réplica cuya oportunidad me ha sido ofrocida.

1. Comienza Larrañaga por corregir con buen tino mi error sobre la primera asistencia del titular de Tarazona a un concilio, que debe situarse en 589. No afecta sin embargo esto en nada a mi razonamiento sobre los ejemplos de Tarazona y Calahorra y el carácter excepcional de las fuentes que nos dan noticia de tales episcopados antes del III Concilio de Toledo. En cuanto a su presentación de los datos de asistencias, no veo qué ventaja tiene darlos en términos globales para todo el período visigodo en lugar de distinguir sínodos provin- 
ciales y nacionales, y etapas en la historia de estas reuniones. Tal vez se trate de destacar mejor que cuatro asistencias en doscientos años constituirían una singularidad significativa, un caso atípico incluso en el marco de la Tarraconense, la más absentista de las provincias peninsulares. Pero, dejando de lado que creo haber mostrado que sólo cabe hablar de absentismo sistemático en los 23 años que van de Toledo IV a Toledo $\mathrm{X}$, no parece que comparado con los dos siglos que prefiere computar Larranaga tres o cuatro asistencias más (Tarazona o Huesca) sean tampoco gran cosa. Es cierto que siete es casi el doble de cuatro, pero con estas magnitudes no es decir mucho. Hasta tal punto pretender que estas diferencias son sorprendentes es un poco forzado, que llamo la atención sobre el hecho de que, dados los concilios cuyos asistentes desconocemos, ni siquiera se puede afirmar con certeza absoluta que Tarazona o Huesca hayan asistido a más concilios que Pamplona.

2. Larrañaga se pregunta por las ausencias de Huesca, Tarazona, Calahorra, Oca - - y quizá Pamplona en el caso de que ya tenga obispo - a los cuatro concilios provinciales habidos en el oriente de la Tarraconense entre 516 y 542. Entiende que no hay motivos a priori para que no asistan y propone como causa hipotética de sus ausencias una situación de inestabilidad general del dominio godo en todo el occidente de la provincia, de la que se aprovechan poderes locales y que tiene relación con los primeros signos de conflicto en torno a los vascones. Es un falso problema. Basta con mirar fuera de la Tarraconense para ver que el concilio de Valencia de 549 no reúne sino a seis obispos y un arcediano en la provincia con mayor número de sedes de la Iglesia hispánica. $\mathrm{O}$, si se quiere, en el reino suevo, perfectamente en paz, el primero de Braga de 561 cuenta con sólo ocho representantes (frente a los doce de Braga II en 572, donde significativamente se distinguen los prelados de los sinodos lucense y bracarense, dentro de una misma provincia). La Tarraconense no es la única provincia en celebrar asambleas reducidas en esta etapa. Dicho lo cual, se observará que aunque no fuera, como yo creo, un falso problema la no asistencia de las sedes occidentales a los concilios de este período, la propuesta explicativa de Larrañaga es dificilmente aceptable. Según éste, la clave reside en que el poder visigodo no es capaz de imponer o facilitar a los obispos su asistencia a una iglesia provincial que percibirían como extraña por estar sometida a un poder político extraño. En cuanto a imponer, no se ve muy bien qué interés pueden tener en ello los dirigentes visigodos arrianos. Para que esto fuera creíble haría falta que lo mostraran en alguna otra provincia, lo que no ocurre. En cuanto a facilitar, no es verosímil que los obispos de Tarazona o Huesca, por ejemplo, no puedan ir hasta Zaragoza o Lérida en todos estos decenios. Máxime cuando está fuera de duda que, antes de que Leovigildo lleve a cabo su primera campaña en el valle del Ebro, el obispo de Huesca posee, gestiona efectivamente y recorre a menudo un patrimonio que se ex-

Sobre in Iglesia Medieval Hispania Sacra 49 (1997) 
tiende de los valles pirenaicos hasta Zaragoza y Lérida. Y por fin, para que tuviera alguna verosimilitud el que los obispos de Tarazona, Calahorra, Huesca u Oca perciban como extraños a los de Zaragoza, Barcelona, o al metropolitano de Tarragona, convendrua alguna prueba o indicio. Nada objeta en cambio Larrañaga a mi lectura de los concilios provinciales posteriores a 589.

3. Sobre la campaña de Leovigildo de 581 y la erección del obispado de Pamplona, Larrañaga no se pronuncia definitivamente. Le parece plausible la existencia de una comunidad cristiana en Pamplona desde el Bajo Imperio, pero «dado que no hay atestaciones de obispos con anterioridad a (...) 589 , cabría en principio retrasar la erección de una sede episcopal en Pamplona hasta que ésta pasa a manos visigodas» [el subrayado es suyo]. $E$ insiste en que ningún argumento suficiente se opone a la hipótesis que hace derivar a uno de la otra. Pero Larrañaga sabe bien que hay hipótesis sostenibles tanto tiempo como se quiera, a condición, eso sí, de olvidar el principio de economía en las explicaciones que él mismo invoca en su nota 90 -en la que, dicho sea de paso, repite lo que yo ya dije-. Para aceptar la que él no desecha, hay que admitir previamente y de manera encadenada : a) Que al contrario que las sedes que la rodean y que tampoco van a los concilios antes de 589, la comunidad cristiana de Pamplona es incapaz de dotarse de un obispo sin la actuación de una autoridad exterior. b) Que la campaña de Leovigildo ha afectado a Pamplona, a pesar de que nadie tiene ni la más remota idea fundada de en qué parte de Vasconia ha tenido lugar la acción militar. Dicho sea de paso, ihay algun indjcio, que no ya prueba, de que Pamplona haya estado fuera del control visigodo antes de 589? c) Que Leovigildo, al contrario de lo que ha hecho en el reino suevo, es incapaz de instalar un obispo arriano. d) Que en cambio, después de su muerte pero antes de Toledo III, las autoridades ( $i$ de ocupación?) dan a la comunidad cristiana de Pamplona un obispo. En cuanto a que esto cuadre con «las maneras de los monarcas visigodos en su práctica política», ¿cuántos de los casi ochenta obispados hispánicos han sido fundados, no en Época visigoda, sino por decisión de la corona y de sus representantes? Las efimeras fundaciones de Wamba, rápidamente anuladas, no parece que puedan citarse como ejemplo de la política corriente del reino. Y desde luego, la intervención del rey en el nombramiento de obispos nada tiene que ver con esto.

4. Me permitirá Larrañaga una precisión terminológica, en torno a la ausencia de noticias de campañas militares entre 621 y 673 . Cita literalmente una frase en la que yo afirmo que es el reflejo lógico de la penuria de fuentes cronísticas o historiográficas en general entre la obra đe Isidoro y la de Julián de Toledo. «Es posible que esto sea así [prosigue inmediatamente Larrañaga], aunque, puestos a pensar, cabría igualmente conjeturar que..." Que para ese período la situación de las fuentes de este tipo es de penuria, es un hecho. $Y$ 
que esto se refleje en que no dispongamos de informaciones relativas a campañas militares en Vasconia -teniendo en cuenta que todas las que tenemos provienen de este tipo de fuentes - no es una conjetura. En cuanto a lo que Larrañaga conjetura a continuación, en el sentido de que la falta de una actividad historiográfica comparable a la de Isidoro o Julián durante esos años refleje «la política vacilante y medrosa de una realeza goda atrapada en sus propias contradicciones», no sólo «vacilante» y «medroso» son adjetivos que cuadran francamente mal con, por ejemplo, Chindasvinto, sino que hacer derivar la producción historiografica de la salud política del estado en la Antigüedad, sea clásica o tardía, parece poco meditado.

5. Entiende Larrañaga que la relación entre la cronología de las campañas militares y las de la asistencia conciliar no es vaga. Un décalage de nueve o diez años sería aceptable, dado que «tales acciones de fuerza levan aparejadas por lo común [el subrayado es nuestro] otras medidas de tipo estratégicotáctico (reforzamiento del dispositivo de defensa, puesta en marcha del aparato fiscal y administrativo, adoctrinamiento ideológico mediante erección de nuevas sedes episcopales, etc." ¿Dónde y cuándo? ¿Cuándo el ejército visigodo $\longrightarrow$ el ostrogodo, o el suevo, o el merovingio- ha tomado una ciudad y se ha empeñado en el adoctrinamiento ideológico erigiendo una nueva sede episcopal? No contribuye al rigor de una argumentación presentar como algo común aquello cuya existencia se quiere demostrar.

6. Pero, si no he comprendido mal, de acuerdo con la hipótesis que le parece finalmente más razonable a Larrañaga, no se trataría tanto de que el ejército visigodo ponga y reponga un obispado, como de que el control de la ciudad y sus vías de comunicación con el sur son la condición necesaria para que el titular de Pamplona asista a los concilios, sea porque apunta «tendencias filogóticas» y en otras circunstancias no se lo permiten los poderes locales reacios a la dominación goda, sea porque el poder visigodo le obliga a ello con vistas a integrar la sede en los engranajes del reino. Es decir: a) Tras la campaña de Leovigildo se erige una sede como intrumento de dominación e integración en el estado visigodo que luego, retomado el control de la ciudad por quienes se resisten con uñas y dientes a tal estado, es tolerada por éstos (convendrá conmigo Larrañaga en que si los obispos se retiraran con las tropas godas, no faltarían a un solo concilio) b) Suintila no es capaz de asegurar convenientemente o de modo duradero el control en 621 puesto que no hay obispos de Pamplona en los concilios siguientes. c) Wamba recupera el dominio de la ciudad e incluso ejercería «una cierta delicada presión» (n. 85) sobre el obispo de Pamplona, que sin embargo no va al concilio de 681 y sí al siguiente de 683. Así pues, las autoridades visigodas de una Pamplona militarmente ocupada, interesadas al parecer en la participación de su obispo en los concilios, toleran que

Sobre la Iglesia Medieval Hispania Sacra 49 (1997) 
falte a uno en el que la corona está, como se sabe, particularmente interesada, y autorizan el envío de un delegado de bajo rango al sínodo siguiente. Se pueden hacer equilibrios para salvar las dificultades que todo esto supone. Pero convendría no olvidar que: a) Desde la llegada de las tropas de Eurico hasta la batalla de Guadalete, no hay ni una sola prueba de que ni el núcleo urbano ni el conjunto de la civitas de Pamplona haya estado jamás en manos de nadie opuesto al reino visigodo - jatención! digo al reino y no a tal o cual facción de la nobleza-. b) No hay ni una sola prueba de que ningún rey visigodo haya intentado nunca tomar Pamplona - salvo quizás Rodrigo-- Y pretender que las ausencias y presencias de los obispos prueban tales cosas es construir una argumentación circular.

7. En la lectura de la Historia Wambae regis, Larranaga me atribuye una originalidad que no tengo. No he sido ni mucho menos el primero en presentar lo esencial del orden de los acontecimientos que recojo, y creo señalarlo así en mis notas 56 y 57. En cualquier caso el texto de Julián está ahí y que Wamba decide atacar Vasconia cuando ya conoce el estallido de la revuelta me parece fuera de duda. Que la participación de los vascones de Lupo implique una "participación conjunta de vascones de ambos lados de los Pirineos», no es que no me plazca, como dice Larrañaga, es que está por demostrar. Ahora bien, que de la conexión de la Vasconia peninsular con la revuelta del Nordeste del reino que yo sostengo, se deduzca que yo no advierto nada peculiar en la Vasconia de estos siglos, como Larrañaga pone en mi pensamiento, va un trecho. Lo que ocurre es que yo me ocupo en mi artículo del obispado y logicamente, de la civitas de Pamplona. Y ahí sí creo que la actitud de la aristocracia local es esencialmente la misma que la de las otras civitates de la Tarraconense en los decenios finales del reino de Toledo.

8. Acepta Larrañaga en su nota 119 la lectura que hago del in Tarraconensem provinciam accedere del Iudicium in tyrannorum perfidia promulgatum. Pero, «puestos a exigir rigor [prosigue Larrañaga], cabría exigírselo también a Isidoro, que habla de incursiones de los Vascones en la provincia Tarraconense (Hist. Goth., 63). Pero ies que, en rigor, cabe desde Vasconia hacer incursiones en la Tarraconense? $\mathrm{O}$ ¿será que en el horizonte mental del hispalense la Vasconia de los Vascones problemáticos (...) había dejado de asociarse con la Tarraconense clásica» [los subrayados son del autor]. Veamos lo que escribe Isidoro : expeditionem contra incursus Vasconum Terraconensem prouinciam infestantium... Es decir, «expedición contra las correrías (o las incursiones, o las acometidas, $o$ los asaltos) de los vascones que asolan (o infestan, $o$ causan estragos en) la provincia tarraconense» ¿Dónde está la dificultad? Sabe bien Larrañaga que no vale lo mismo un acusativo con in delante que sin ninguna preposición, y Terraconensem prouinciam no es sino el objeto de infestantes. 
Y por supuesto que habitantes de la Tarraconense pueden llevar a cabo correrías, saqueos, masacres e incursiones en su provincia - Vasconia incluida-. En cuanto al horizonte mental de Isidoro, mal encaja que no conciba Vasconia como parte de la Tarraconense con la existencia de un obispado que, según Larrañaga, los visigodos están empeñados en hacer participar en las reuniones de la Iglesia hispánica.

9. Insiste Larrañaga en que los vascones de la Historia Wambae aparecen como agentes exteriores al reino visigodo. Pero, ¿qué vascones? Parece fuera de duda que los sublevados compran la participación militar de vascones. Pero si se lee la Historia Wambae, y sobre todo el pasaje que alega precisamente Larrañaga en su nota 118 y los que le siguen inmediatamente, se notará que se distingue la ayuda mercenaria de vascones y «francos» citada al narrar los acontecimientos ultrapirenaicos, de los vascones que Wamba se apresta a someter en esos mismos momentos -cum haec intra Gallias agerentur- de este lado de las montañas. En mi opinión, convendría demostrar algo que Larrañaga y otros dan por hecho, a saber que el conjunto de los vascones, los de la Vasconia clásica como los de la costa cantábrica o los de Aquitania, actúan, reaccionan y funcionan como una sola entidad.

10. A estas alturas, el lector habrá percibido que, si el debate empezó con el obispado de Pamplona, en el fondo estamos hablando de otra cosa. Más que rebatir y mostrar los eventuales errores de mi propuesta consistente en explicar el comportamiento de la sede vascona a la luz del comportamiento general de la Iglesia de su provincia, y en general, de la Iglesia hispánica, lo que hace Larrañaga es poner de manifiesto que tal propuesta no encaja con su visión de la Vasconia tardoantigua. Lo cual es bien cierto. Sobre cuál es mi interpretación de este período, no es desde luego una réplica puntual el lugar de exponerla. Sé sin embargo de la amabilidad de Larrañaga, y no dudo de la benevolencia del lector, quienes me permitirán -si en ello tienen interés-- que les remita a un trabajo que debe ver la luz en cuestión de meses. Sí quisiera, de todos modos, apuntar un problema general que se deja ver en este debate y que me parece fundamental en el sentido más estricto del término. Desde hace décadas se han alegado textos literarios como testimonios de una determinada situación social, cultural, religiosa o política de Vasconia. Y a menudo, se ha procedido a una acumulación en la que se suman sin discriminación fragmentos de poesías con pasajes historiograficos y fragmentos epistolares, como si tal acumulación, que produce a veces la impresión de abundancia de pruebas concordantes, fuera sinónimo de rigor. Cuesta entender por qué el ejercicio inexcusable de crítica de las fuentes se ha eludido para Ja historia vasca antigua. En las páginas que yo agrupé bajo el epígrafe «historiografía y retórica», traté no de «hacer creer» nada, como dice Larrañaga con una poco afortunada 
expresión, sino de valorar el fragmento relativo a la campaña de Wamba a la luz de los códigos literarios y de la tradición en que se mueve su autor, así como de sus intenciones. Yo diría que sin rendir cuenta de esto, mal se puede utilizar el texto en una argumentación. Por supuesto que mi análisis puede ser erróneo, pero me habría gustado que Larrañaga hubiera mostrado en qué. En cambio, éste se limita, en su nota 22 a hablar de una cierta moda (sic) tendente a «cuestionar el valor probativo de los textos desde el punto en que se evidencia en ellos cualquier traza de utilización de estereotipos o clichés literarios». Y se lanza, tanto en esta nota como en la parte más directamente relacionada con mi lectura del texto de Julián, a una reflexión sobre la función general del cliché, su relación con las necesidades expresivas de un grupo, etc., para continuar planteando conjeturas sobre el uso de topicos por los autores que se han referido a los vascones. Yerra Larrañaga. No estamos hablando de textos apócrifos o de oscuros y desconocidos escritores. Hablamos de nombres de primer orden en la literatura latina : Prudencio, Paulino de Nola, Venancio Fortunato, Isidoro... Son cientos los trabajos que desde hace muchos años han dedicado filologos e historiadores de la literatura a analizar su métodos, sus fuentes, sus referentes, sus juegos literarios, su vocabulario, sus relaciones, sus intereses, su visión del mundo, sus biografías. Ahí es donde hay que mirar. Acabaré con un ejemplo somero. Desde que Caro Baroja llamó la atención en Los pueblos del Norte sobre los versos en que Paulino de Nola mencionaba a los vascones del Pirineo ( $E p .31$ en la edición de Peiper), tal pasaje se ha aducido repetidamente, con variados matices, como prueba del carácter ajeno a la romanidad de este pueblo. Más mesurado, Larrañaga entiende que Paulino y Ausonio (aunque no veo muy bien por qué menciona a este último, que se limita a evocar el bosque del vascón en relación con los albergues nevados del Pirineo) muestran su «extrañeza ante su [de los vascones] penosa situación cultural, sin que ésta en ningún caso rebase la consideración de un problema interior al Estado romano». Más adelante Larrañaga nos habla de los «días (...) en que Prudencio o sus coetáneos Ausonio y Paulino hacían retórica (sic) en punto a la penosa situación cultural de los Vascones» [los subrayados son en ambos casos del autor]. De entrada, nunca hablan Ausonio y Paulino de otra cosa que no sean los vascones que habitan las montañas. Afirmar que se refieren a «los Vascones», como si hablaran de toda Vasconia es gratuito. En segundo lugar, otras partes de la misma carta de Paulino desmienten (Quae regio agreste ritu caret?) que la situación de estos montañeses le parezca extraña. Pero sobre todo, por algún motivo se ha pasado por alto que desde la edición de Hartel, es decir desde hace más de un siglo, la identificación del Integer uitae scelerisque purus permite ver que Paulino está remedando en el pasaje en cuestión a Horacio (Carm. 1, 22), en una oda que - es casi ofensivo para ellos señalarloremitente y destinatario de los versos conocían de memoria desde su adoles- 
cencia. Oda que sirve igualmente de punto de partida a otro escritor cristiano, Lactancio (Diuin. inst., 5, 17), para desarrollar un tema no lejano del de Paulino. Para éste - y propongo al lector que compare los versos de Horacio con los de Paulino- los vascones del Pirineo no son más que el pretexto para desarrollar un juego literario entre antiguo alumno y maestro. Juego que tiene sus reglas, y exige en este caso, con toda evidencia, destacar con los trazos más acentuados posibles la imagen negativa elegida para servir de contraste al hombre integer vitae scelerisque purus ¿Por qué los vascones para esto? Porque lo toma de la ironía que Ausonio le ha dirigido previamente. Y éste a su vez se refiere a los albergues nevados del Pirineo vascón porque, escribiendo desde Aquitania al amigo que marchó a Hispania, alude a la mudanza, física pero también espiritual, que le ha separado dolorosamente de éste. Nada más -y nada menos-. Dicho lo cual, me parece muy probable que los pasos pirenaicos den cobijo a ladrones miserables de costumbres salvajes, como son por otro lado los montañeses en general a los ojos de un romano cultivado. Lo mismo ocurre en casi todas la montañas del mundo antiguo, como es bien sabido. Que Paulino - que niega explícitamente haber estado entre ellos- los utilice en sus versos como excusa para su juego, es perfectamente comprensible. Ahora bien, no ya que vea en el estado de los vascones del Pirineo un problema, sino simplemente que le interesen lo más mínimo, a él como a Ausonio, es harto dudoso; como lo es el que tengan ningún interés en describirlos como si —subrayémoslo - la poesía se rigiera por las mismas normas que la geografía. La cuestión no es por qué Paulino habla así de los vascones. La cuestión es que Ausonio y Paulino están hablando de otra cosa. 